\title{
Tuning Tetrazole Photochemistry for Protein Ligation and Molecular Imaging
}

\author{
Fay, Rachael ; Holland, Jason P
}

\begin{abstract}
Photochemistry provides a wide range of alternative reagents that hold potential for use in bimolecular functionalisation of proteins. Here, we report the synthesis and characterisation of metal ion binding chelates derivatised with disubstituted tetrazoles for the photoradiochemical labelling of monoclonal antibodies (mAbs). The photophysical properties of tetrazoles featuring extended aromatic systems and auxochromic substituents to tune excitation toward longer wavelengths (365 and $395 \mathrm{~nm}$ ) were studied. Two photoactivatable chelates based on desferrioxamine B (DFO) and the aza-macrocycle NODAGA were functionalised with a tetrazole and developed for protein labelling with $89 \mathrm{Zr}, 64 \mathrm{Cu}$ and $68 \mathrm{Ga}$ radionuclides. DFO-tetrazole (1) was assessed by direct conjugation to formulated trastuzumab and subsequent radiolabelling with 89Zr. Radiochemical studies and cellular-based binding assays demonstrated that the radiotracer remained stable in vitro retained high immunoreactivity. Positron emission tomography (PET) imaging and biodistribution studies were used to measure the tumour specific uptake and pharmacokinetic profile in mice bearing SK-OV-3 xenografts. Experiments demonstrate that tetrazole-based photochemistry is a viable approach for the light-induced synthesis of PET radiotracers.
\end{abstract}

DOI: https://doi.org/10.1002/chem.202100061

Posted at the Zurich Open Repository and Archive, University of Zurich ZORA URL: https://doi.org/10.5167/uzh-213028

Journal Article

Accepted Version

Originally published at:

Fay, Rachael; Holland, Jason P (2021). Tuning Tetrazole Photochemistry for Protein Ligation and Molecular Imaging. Chemistry - A European Journal, 27(15):4893-4897.

DOI: https://doi.org/10.1002/chem.202100061 


\title{
Tuning tetrazole photochemistry for protein ligation and molecular imaging
}

\author{
Rachael Fay ${ }^{[a]}$ and Jason P. Holland ${ }^{*[a]}$
}

\begin{abstract}
Photochemistry provides a wide range of alternative reagents that hold potential for use in bimolecular functionalisation of proteins. Here, we report the synthesis and characterisation of metal ion binding chelates derivatised with disubstituted tetrazoles for the photoradiochemical labelling of monoclonal antibodies (mAbs). The photophysical properties of tetrazoles featuring extended aromatic systems and auxochromic substituents to tune excitation toward longer wavelengths (365 and $395 \mathrm{~nm}$ ) were studied. Two photoactivatable chelates based on desferrioxamine B (DFO) and the aza-macrocycle NODAGA were functionalised with a tetrazole and developed for protein labelling with ${ }^{89} \mathrm{Zr},{ }^{64} \mathrm{Cu}$ and ${ }^{68} \mathrm{Ga}$ radionuclides. DFO-tetrazole (1) was assessed by direct conjugation to formulated trastuzumab and subsequent radiolabelling with ${ }^{89} \mathrm{Zr}$. Radiochemical studies and cellular-based assays binding demonstrated that the radiotracer remained stable in vitro retained high immunoreactivity. Positron emission tomography (PET) imaging and biodistribution studies were used to measure the tumour specific uptake and pharmacokinetic profile in mice bearing SK-OV-3 xenografts. Experiments demonstrate that tetrazole-based photochemistry is a viable approach for the light-induced synthesis of PET radiotracers.
\end{abstract}

The photochemical reactivity of tetrazoles was first reported by Huisgen et al. in 1967. [1] Light-induced activation of diaryltetrazoles populates an electronic excited state that undergoes rapid loss of $\mathrm{N}_{2}(\mathrm{~g})$, to form a highly reactive nitrile imine. This nitrile imine intermediate can behave as a 1,3-dipole and participate in cycloaddition reactions ${ }^{[2]}$ or as an electrophile, reacting with native nucleophiles on protein. ${ }^{[3]}$ In 2008, the group of Qing Lin reported the use of tetrazoles for labelling of posttranslationally modified proteins via photoinduced [3+2] cycloadditions with alkene substituents. ${ }^{[4]}$ This remarkable and fast reaction was described as a 'photo-click' process and is fluorogenic, generating emissive pyrazoline products. ${ }^{[5]}$ Subsequent work used genetically encoded artificial amino acids bearing alkenes ${ }^{[6]}$ and cyclopropenes ${ }^{[7]}$ for site-specific, photoinduced labelling of pre-modified proteins in vitro and in vivo. One of the attractive features of tetrazole-alkene photochemistry is that reactivity can be modified to increase coupling rates via structural and frontier orbital control on the tetrazole ${ }^{[8-11]}$ or the alkene partners. ${ }^{[12,13]}$ However, a drawback of tetrazole photochemistry is the need to use short wavelength light ( 302 $\mathrm{nm}$ ) to form the nitrile imine which is potentially damaging to proteins like mAbs. ${ }^{[14,15]}$

[a] R. Fay, Prof. Dr J. P. Holland

University of Zurich, Department of Chemistry, Winterthurerstrasse

190, Zurich, CH-8057, Switzerland

Correspondence to:

E-mail: jason.holland@chem.uzh.ch

Tel: +41.44.63.53.990

Website: www.hollandlab.org

Supporting information is available
The photo-click reaction between tetrazoles and alkenes was reported to be bioorthogonal. ${ }^{[5,16]}$ However, Huisgen et al. noted the reactivity of thermally-induced nitrile imines with thiophenol in 1961. ${ }^{[3]}$ More recently, the biorthogonality of the 'photo-click' chemistry has been questioned. Detailed experimental evidence confirmed that the electrophilic nitrile imine produced via photochemical activation from tetrazoles reacts with nucleophilic amino acid residues in proteins. ${ }^{[17,18]} \mathrm{Li}$ et al. demonstrated the photochemical induced reactivity of tetrazoles toward a range of carboxylic acids including pent-4-enoic acid, $\mathrm{AcOH}$, free alanine and proteins labelled at Glu residues. ${ }^{[17]}$ Whilst the authors also reported reactivity toward a range of biologically relevant nucleophiles such as thiols, amines and alcohols, they noted that at physiological $\mathrm{pH}$, carboxylic acids reacted preferentially with the nitrile imine, even outcompeting the cycloaddition process. Similarly, Zhao et al. reported the photo-induced reactivity of tetrazoles with propionic acid and a protected Asp derivative. ${ }^{[18]}$ Competition experiments with amino acids containing phenol, thiol, and amino functional groups, reduced the yield of the reaction between their model tetrazole and Boc-Asp-OtBu, indicating that other nucleophiles can also react with the nitrile imine. ${ }^{[18]}$ Following these studies, the photo-induced reactivity of tetrazoles with thiols (mercaptoethanol) and amino acids (Trp, Pro, His, Ser, Asn, Tyr, Asn) was reported. ${ }^{[19-21]}$

Until recently, the combination of radiochemistry and photochemistry has received minimal attention. Early work established that compounds radiolabelled with ${ }^{99 m} \mathrm{Tc},{ }^{18} \mathrm{~F},{ }^{188} \mathrm{Re}$ and ${ }^{111} \mathrm{In}$ radionuclides could be functionalised with substituted (perfluoro-, nitro-) and non-substituted aryl azide $\left(\mathrm{ArN}_{3}\right)$ for photochemically induced labelling of different bioactive molecules. ${ }^{[22-31]}$ Sun et al. used the photo-induced cycloaddition process and labelled an alkene-functionalised, tumour-specific peptide with a modified tetrazole which allowed ${ }^{68} \mathrm{Ga}$ and ${ }^{64} \mathrm{Cu}$ radiolabelling for PET and optical imaging in a glioblastoma model. ${ }^{[32]}$ Our group has also explored the use of photoactivatable chelates bearing an aryl azide to make viable ${ }^{68} \mathrm{Ga}$ and ${ }^{89} \mathrm{Zr}$ PET radiotracers via direct functionalisation of mAbs. ${ }^{[33-36]}$

Here, we demonstrate that the photophysical properties of tetrazoles can be tuned through synthetic control over the arylene substituents to facilitate the rapid and direct, bimolecular protein labelling at wavelengths in the UVA region of the spectrum. Twostep photochemical conjugation and radiolabelling produced ${ }^{89} \mathrm{Zr}$ labelled trastuzumab for PET imaging of human epidermal growth-factor receptor 2 (HER2/neu) expression in tumours. 
Tetrazole compounds $\mathbf{7}, \mathbf{9}, \mathbf{1 0}$, and 12 (Figure 1) were synthesised by reacting phenylsulfonylhydrazones with arylene diazonium salts (generated in situ) and isolated in moderate yields (2342\%). ${ }^{[37]}$ Compound 8 was synthesised from compound 9 by nucleophilic aromatic substitution of the bromosubstituent by using NaSMe. Compound
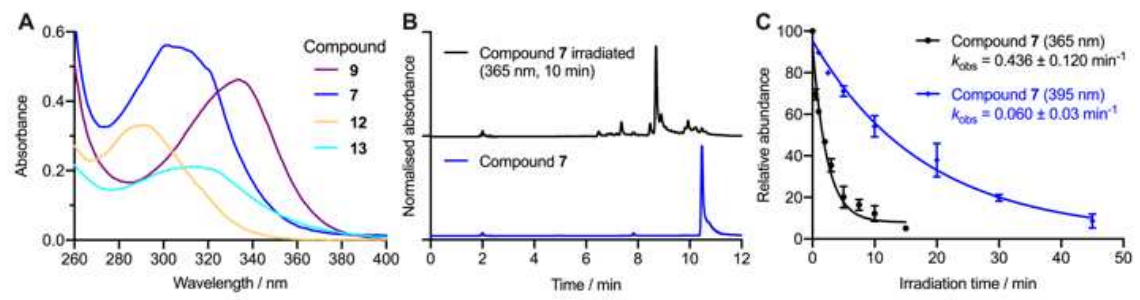
13 was synthesised in two-steps involving isolation and deprotection of the corresponding OBn derivative (14). Efforts to synthesise the anthracene analogue (11) were not successful. Full experimental details and characterisation data are given in the supporting information (Schemes S1-S8, Figures S1-S36)

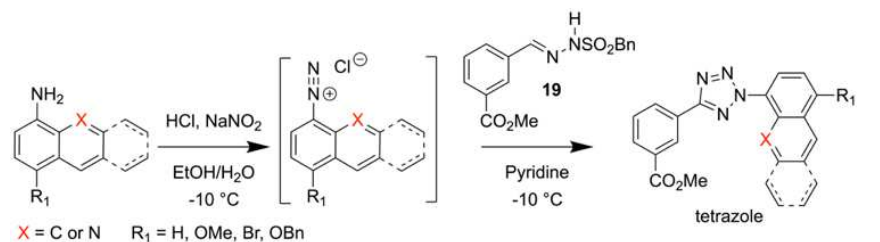

To apply compound $\mathbf{7}$ in the photoradiochemical synthesis of ${ }^{89} \mathrm{Zr}$-labelled mAbs, we synthesised the desferrioxamine-tetrazole derivative, compound 1 (Scheme S8 and Figures S31-S36). DFO is a hexadentate chelate which is used in clinical PET with ${ }^{89} \mathrm{Zr}$ $\mathrm{mAbs}$ to coordinate the ${ }^{89} \mathrm{Zr}^{4+}$ metal ion (half-life, $t_{1 / 2}=78.41 \mathrm{~h}$ ). ${ }^{[42]}$ In addition, to increase radiochemical scope, we also synthesised a NODAGA-based tetrazole (4) for ${ }^{68} \mathrm{Ga}$ and ${ }^{64} \mathrm{Cu}$ radiochemistry (Scheme S7 and Figures S29-S31). Full details of synthesis and radiosynthesis of $\left[{ }^{\text {nat } / 68} \mathrm{Ga}\right] \mathrm{Ga}-4,\left[{ }^{\text {nat } 64} \mathrm{Cu}\right] \mathrm{Cu}-4^{-}$and $\left[{ }^{\text {nat } / 68} \mathrm{Ga}\right] \mathrm{Ga}-1$ are presented in the supporting information (Figures S39-S41). Details on the photochemical conjugation of compound 4 to human serum albumin (HSA) and dinutuximab (a chimeric mAb against the disialoganglioside GD2 in neuroblastoma) and radiolabelling with ${ }^{68} \mathrm{Ga}$ and ${ }^{64} \mathrm{Cu}$, respectively, are also shown (Figures S42-S45).

The DFO analogue (compound 1) was synthesised from (7) in 4-steps with an overall yield of $31 \%$. Briefly, compound 7 was saponified and a Boc protected PEG linker was coupled to yield compound 3 (Scheme S8). Deprotection of the Boc group revealed the free amine (2) which was then coupled with DFOsuccinate via amide bond formation to yield the desired compound 1. Photophysical experiments with (1) indicated that the compound retained the photoactivity seen for the tetrazole core $\left(\varepsilon_{365}=312 \mathrm{M}^{-1} \mathrm{~cm}^{-1}, k_{\text {obs }}(365 \mathrm{~nm})=1.88 \pm 1.09 \mathrm{~min}^{-1} ; \varepsilon_{395}=\right.$ $200 \mathrm{M}^{-1} \mathrm{~cm}^{-1}, k_{\text {obs }}(395 \mathrm{~nm})=0.19 \pm 0.09 \mathrm{~min}^{-1}$, Figure S38). The calculated photochemical quantum yields $\left(\phi_{p}\right)$ for $(1)$, which is a measure of the efficiency of light-induced activation, were $2.2 \pm 0.4 \%$ and $0.23 \pm 0.04 \%$ at 365 and $395 \mathrm{~nm}$, respectively. Complexation of ${ }^{\text {nat }} \mathrm{Zr}^{4+}$ with (1) was achieved by using standard methods and the ${ }^{\text {nat }} \mathrm{Zr}-1^{+}$complex was characterised by HRMS and HPLC. The radioactive complex, ${ }^{89} \mathrm{Zr}-1^{+}$was prepared at $23^{\circ} \mathrm{C}$ in $\leq 10$ minutes and was characterised by using radio-iTLC, and by radio-HPLC which gave a single peak in the chromatogram (Figure 3). Co-injection of ${ }^{89} \mathrm{Zr}-1^{+}$with the nonradioactive complex measured by electronic absorption showed coincident retention times in HPLC. substituent (9) induced the greatest shift in $A_{\max }$ to $332 \mathrm{~nm}(+42$ $\mathrm{nm}$ with respect to the unsubstituted naphthalene-derivative (12), $\mathrm{A}_{\max }=290 \mathrm{~nm}$; Figure 2A). ${ }^{[39,40]}$ Kinetic studies on the photoactivation revealed that the rates of photolysis increased with increasing molecular absorption coefficient (Table S1). Irradiation of compound $7\left(\varepsilon_{365}=298 \mathrm{M}^{-1} \mathrm{~cm}^{-1}\right)$ with light at 365 $\mathrm{nm}$ induced a rapid first-order decomposition with an observed rate constant, $k_{\text {obs }}(365 \mathrm{~nm})=0.44 \pm 0.12 \mathrm{~min}^{-1}$. Although compound 8 displayed the largest red-shift and fastest rate of photolysis, thioethers are susceptible to oxidation in vivo. ${ }^{[41]}$ Therefore, compounds was selected for further applications in protein ligation.

Figure 2. Photophysical and photochemical data on tetrazoles 7, 9 and 13. A) Electronic absorption spectra recorded in DMSO. B) HPLC chromatograms before and after photolysis of compound 7. C) Kinetic plots showing the relative change in the concentration of compound 7 versus time during extended photolysis at 365 and $395 \mathrm{~nm}$.
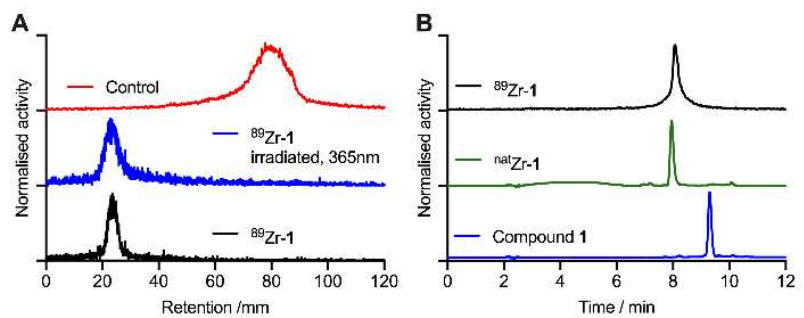

Figure 3. Chromatographic data on the complexation of ${ }^{n a t / 89} \mathrm{Zr}^{4+}$ by compound 1. A) Radio-iTLC data ${ }^{89} \mathrm{Zr}-1^{+}$before (black) and after (blue) irradiation and a control (red, [ $\left.{ }^{89} \mathrm{Zr}\right][\mathrm{Zr}(\mathrm{DTPA})]^{-}$. B) Analytical HPLC chromatograms for 1 (blue), nat $\mathrm{Zr}-1^{+}$(green) and ${ }^{89} \mathrm{Zr}-1^{+}$(black).

Next, we performed the photochemical conjugation between compound 1 and trastuzumab (formulated as Herceptin ${ }^{\mathrm{TM}}$; 10-to- 
1 chelate-to-mAb ratio, $\mathrm{pH} 7$ ) by irradiating reactions at either 365 or $395 \mathrm{~nm}$ for $10 \mathrm{~min}$ at room temperature (Figure $4 \mathrm{~A}$ ). Aliquots of the crude mixtures were retained for analysis and the DFO-mAb conjugates were isolated from small-molecule impurities by preparative size-exclusion chromatography (SEC). Samples of the crude photoconjugation mixtures were radiolabelled with ${ }^{89} \mathrm{Zr}^{4+}$ giving decay-corrected radiochemical yields (RCYs) of $27.9 \pm 10.5 \%,(n=3)$ and $34.8 \pm 3.0 \%(n=2)$, at 365 and $395 \mathrm{~nm}$, respectively (measured by manual size-exclusion chromatography with PD-10 columns; Figures S46). For a more accurate quantitative analysis we also measured the radiolabelled mixtures by radio-SEC which showed that $15 \%$ of activity was associated with trastuzumab (Figure 4 , panel B, blue trace). Combined with the initial 10-to-1 stoichiometric ratio of reagents, the isolated DFO-mAb conjugate used in future studies had an average of 1.5 accessible DFO ligands per mAb. For in vitro and in vivo experiments, the purified DFO-Np(OMe)-Tz-trastuzumab conjugate was radiolabelled with an excess of ${ }^{89} \mathrm{Zr}$ at pH 8.5 and purified by SEC to give [ $\left.{ }^{89} \mathrm{Zr}\right] \mathrm{ZrDFO}-\mathrm{Np}(\mathrm{OMe})$-Tz-trastuzumab in sterile PBS ( $\mathrm{pH} 7.4)$ with a RCY of $39.8 \%$, a radiochemical purity (RCP) $>95 \%$, and a molar activity of $A_{m}=4.01 \mathrm{MBq} \mathrm{nmol}^{-1}$ of $\mathrm{mAb}$ (Figure 4B).

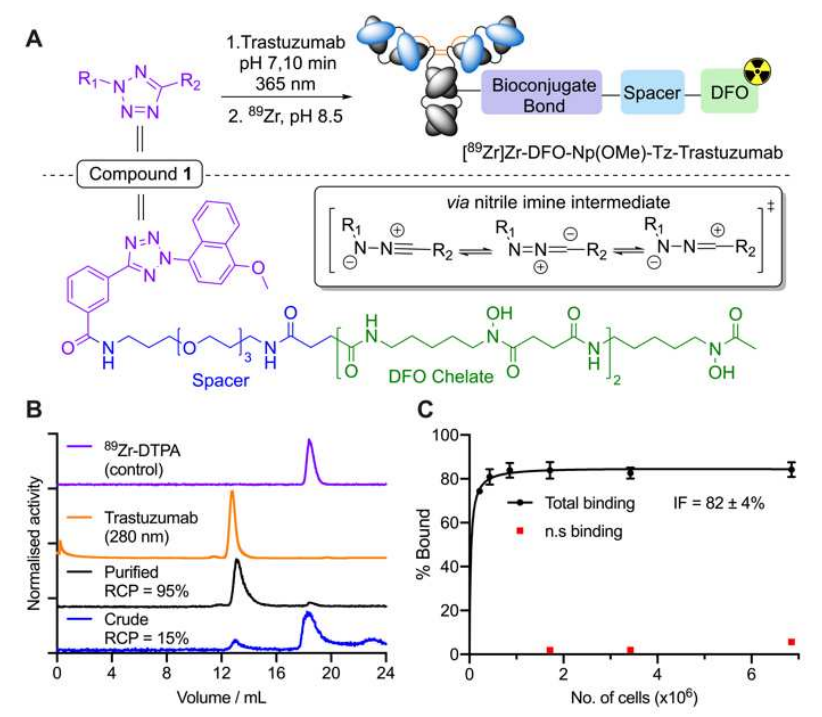

Figure 4. Photochemical conjugation and ${ }^{89} \mathrm{Zr}$-radiolabelling of DFO-Np(OMe)Tz-trastuzumab. A) Schematic showing the structure of compound 1 and the photochemical conjugation reaction with trastuzumab. B) SEC chromatograms showing the crude (blue) and purified (black) samples of the ${ }^{89} \mathrm{Zr}$-mAb, the electronic absorption $(280 \mathrm{~nm})$ profile of trastuzumab, and the elution of $\left[{ }^{89} \mathrm{Zr}\right][\mathrm{Zr}(\mathrm{DTPA})]^{-}$as a control. C) Cellular binding assays showing the specific binding of $\left[{ }^{89} \mathrm{Zr}\right] \mathrm{ZrDFO}-\mathrm{Np}(\mathrm{OMe})$-Tz-trastuzumab to SK-OV-3 ovarian cancer cells (HER2/neu-positive). Control study: n.s. = non-specific binding (achieved by pre-blocking with a 1025-fold excess of non-labelled trastuzumab).

The stability of $\left[{ }^{89} \mathrm{Zr}\right] \mathrm{ZrDFO}-\mathrm{Np}(\mathrm{OMe})$-Tz-trastuzumab was assessed in PBS and human serum (Figure S47-S48). Data indicated that the radiotracer was stable for up to $24 \mathrm{~h}$ at $37^{\circ} \mathrm{C}$ in serum with the main peak in radio-SEC still associated with the ${ }^{89} \mathrm{Zr}$-mAb. In sterile PBS, the radiotracer was stable for 3 days with no change in RCP. Cellular binding studies using SK-OV-3 cells were performed to assess the biochemical integrity of the radiotracer after the photoconjugation and radiolabelling. Binding curve analysis indicated that the $\left[{ }^{89} \mathrm{Zr}\right] \mathrm{ZrDFO}-\mathrm{Np}(\mathrm{OMe})-\mathrm{Tz}-$ trastuzumab sample had an immunoreactive fraction of $82 \pm 4 \%$, and retained specificity toward HER2/neu (Figure 4C). ${ }^{[43]}$
PET imaging and biodistribution studies were performed to measure the pharmacokinetics, tumour specificity and stability of $\left[{ }^{89} \mathrm{Zr}\right] \mathrm{ZrDFO}-\mathrm{Np}(\mathrm{OMe})-\mathrm{Tz}$-trastuzumab in athymic nude mice bearing SK-OV-3 xenografts (Figure 5, Figures S50-S55, Table S2-S3). All animals received the same amount of activity $(0.53 \pm 0.02 \mathrm{MBq})$ but three different mass doses of ${ }^{89}[\mathrm{Zr}] \mathrm{ZrDFO}-$ $\mathrm{Np}(\mathrm{OMe})$-Tz-trastuzumab. Group 1 received the highest molar activity dose $\left(20 \mu \mathrm{g}, A_{\mathrm{m}}=4.01 \mathrm{MBq} \mathrm{nmol}^{-1}\right)$, group 2 received a 13-fold increase in protein dose $\left(A_{m}=0.30 \mathrm{MBq} \mathrm{nmol}^{-1}\right)$ and group 3 received a full blocking dose (72-fold excess, $A_{\mathrm{m}}=0.06 \mathrm{MBq}$ $\mathrm{nmol}^{-1}$ ). SK-OV-3 tumours display extremely high expression of the HER2/neu protein and as consequence, no differences were observed in the PET images and biodistribution data between groups 1 and 2. For example, biodistribution data revealed that $72 \mathrm{~h}$ post-administration the tumour associated activity was $45.8 \pm 14.0 \% \mathrm{ID} \mathrm{g}^{-1}$ for group 1 and $47.0 \pm 7.4 \% \mathrm{ID} \mathrm{g}^{-1}$ for group 2 . In contrast, the tumour uptake in the blocking group was reduced by $\sim 67 \%$ to $15.5 \pm 5.2 \% \mathrm{ID} \mathrm{g}^{-1}$, indicating specific tumour uptake. The tumour-to-tissue contrast was high although activity in the bone was observed in all three groups $\left(11.8 \pm 4.0 \% \mathrm{ID} \mathrm{g} \mathrm{g}^{-1}\right.$, $10.1 \pm 5.7 \% \mathrm{ID} \mathrm{g}^{-1}, 9.1 \pm 3.9 \% \mathrm{ID} \mathrm{\textrm {g } ^ { - 1 }}$ for groups 1,2 , and 3 , respectively). Bone uptake was in line with previous on ${ }^{89} \mathrm{Zr}$ trastuzumab. ${ }^{[44]}$

\section{A}

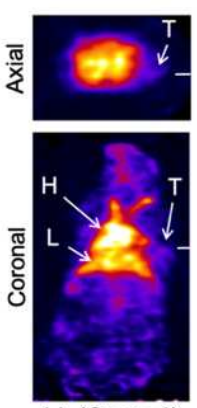

$1 \mathrm{~h}$ (Group 1)
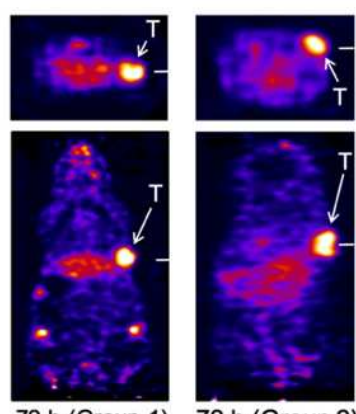

$72 \mathrm{~h}$ (Group 1) $0.0 \% \mathrm{ID} \mathrm{cm} \mathrm{cm}^{-3}$

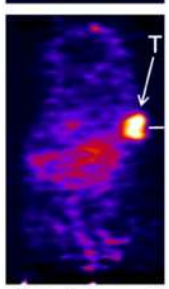

$72 \mathrm{~h}$ (Group 2) $25.0 \%$ ID cm $\mathrm{cm}^{-3}$

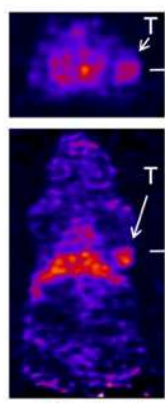

$72 \mathrm{~h} \mathrm{Block}$

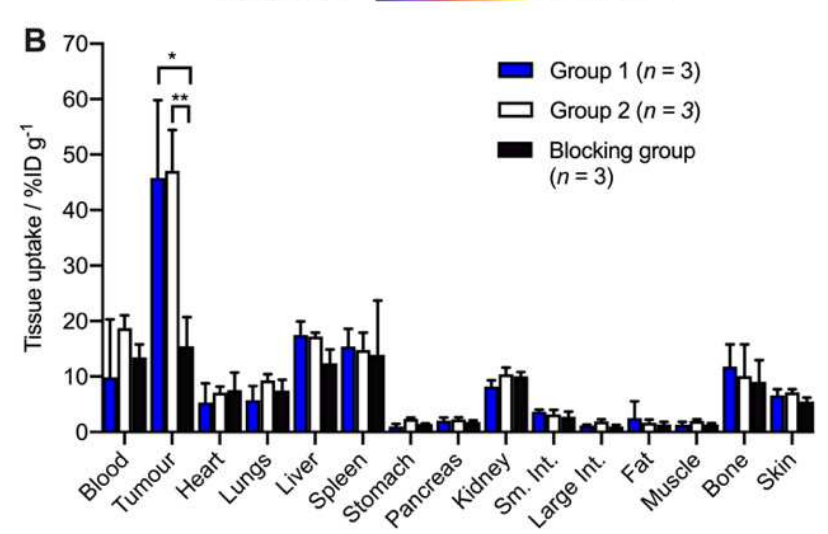

Figure 5. PET imaging and biodistribution data for $\left.{ }^{89} \mathrm{Zr}\right] \mathrm{ZrDFO}-\mathrm{Np}(\mathrm{OMe})-\mathrm{Tz}$ trastuzumab in mice bearing SK-OV-3 tumours. A) Coronal and axial PET images shown through the tumour centre for the three different study groups. $T$ = tumour, $\mathrm{H}=$ heart, $\mathrm{L}=$ liver. $\mathrm{B}$ ) Biodistribution data recorded at $72 \mathrm{~h}$ postadministration.

Whole-body excretion studies were also used to measure the effective half-life of $\left[{ }^{89} \mathrm{Zr}\right] \mathrm{ZrDFO}-\mathrm{Np}(\mathrm{OMe})$-Tz-trastuzumab in each mouse (Figure S56). Measurements indicated that no significant difference in pharmacokinetics was observed between animals in three different dose groups with $t_{1 / 2}$ (eff) equal to $29.8 \pm 0.8 \mathrm{~h}, 35.5 \pm 0.6 \mathrm{~h}$, and $35.2 \pm 7.4 \mathrm{~h}$, respectively. Values were also consistent with prior measurements using ${ }^{89} \mathrm{Zr}$-trastuzumab 
prepared via simultaneous photoradiolabelling with an aryl azide species. ${ }^{[45]}$

In conclusion, the experiments provide irrefutable evidence that a direct photochemical conjugation occurs between the lightinduced nitrile imine and the protein. The nature of the conjugate bonds formed remain uncertain but others have reported convincing evidence that carboxylate, amine and sulfhydryl nucleophiles from amino acids including Glu, Asp, Lys and Cys can attack the nitrile imine intermediate (Scheme S9). ${ }^{[17-21]}$ Tetrazole photochemistry can be adapted for labelling mAbs in the presence of standard formulation buffers (containing high concentrations of trehalose, polysorbate, ascorbic acid, histidine, etc). Some drawbacks of the existing tetrazole compound 1 species include the low water solubility and the lack of chemoand regioselective functionalisation. Further experiments are underway to address these limitations. This work expands the scope of photoradiolabelling and provides an encouraging benchmark demonstrating that ${ }^{89} \mathrm{Zr}$-mAbs can be produced using tetrazole photochemistry.

\section{Acknowledgements}

J.P.H. thanks the Swiss National Science Foundation (SNSF Professorship PP00P2_163683 and PP00P2_190093), the European Research Council (ERC-2015-StG, NanoSCAN676904; ERC-2020-CoG, PhotoPHARMA, 101001734), the Swiss Cancer League (Krebsliga Schweiz; KLS-4257-08-2017), and the University of Zurich (UZH) for financial support. We thank all members of the Radiochemistry and Imaging Science group at $\mathrm{UZH}$.

Keywords: tetrazoles $\cdot$ photochemistry $\cdot$ radiochemistry • antibodies $\cdot$ positron emission tomography

[1] J. S. Clovis, A. Eckell, R. Huisgen, R. Sustmann, Chem. Ber. 1967, 100, 60-70.

[2] J. P. Holland, M. Gut, S. Klingler, R. Fay, A. Guillou, Chem. Eur. J. 2020, 26, 33-48.

[3] R. Huisgen, J. Sauer, M. Seidel, Chem. Ber. 1961, 94, 2503-2509.

[4] W. Song, Y. Wang, J. Qu, M. M. Madden, Q. Lin, Angew. Chemie Int. Ed. 2008, 47, 2832-2835.

C. P. Ramil, Q. Lin, Curr. Opin. Chem. Biol. 2014, 21, 89-95.

[6] W. Song, Y. Wang, J. Qu, Q. Lin, J. Am. Chem. Soc. 2008, 130 9654-9655.

[7] Z. Yu, Y. Pan, Z. Wang, J. Wang, Q. Lin, Angew. Chemie - Int. Ed. 2012, 51, 10600-10604

[8] Y. Wang, W. J. Hu, W. Song, R. K. V. Lim, Q. Lin, Org. Lett. 2008 10, 3725-3728.

[9] Y. Wang, W. Song, W. J. Hu, Q. Lin, Angew. Chemie - Int. Ed 2009, 48, 5330-5333

[10] R. K. V Lim, Q. Lin, Chem. Commun. 2010, 46, 7993-7995.

[11] Z. Yu, L. Y. Ho, Z. Wang, Q. Lin, Bioorganic Med. Chem. Lett. 2011, $21,5033-5036$
Z. Yu, Q. Lin, J. Am. Chem. Soc. 2014, 136, 4153-4156. X. Shang, R. Lai, X. Song, H. Li, W. Niu, J. Guo, Bioconjugate Chem. 2017, 28, 2859-2864.

[14] H. Durchschlag, C. Fochler, B. Feser, S. Hausmann, T. Seroneit, M. Swientek, E. Swoboda, A. Winklmair, C. Wlček, P. Zipper, Radiat. Phys. Chem. 1996, 47, 501-505.

[15] D. I. Pattison, A. S. Rahmanto, M. J. Davies, Photochem. Photobiol Sci. 2012, 11, 38-53.

[16] R. K. V. Lim, Q. Lin, Acc. Chem. Res. 2011, 44, 828-830

[17] Z. Li, L. Qian, L. Li, J. C. Bernhammer, H. V. Huynh, J.-S. Lee, S. Q. Yao, Angew. Chemie Int. Ed. 2016, 55, 2002-2006.

[18] S. Zhao, J. Dai, M. Hu, C. Liu, R. Meng, X. Liu, C. Wang, T. Luo, Chem. Commun. 2016, 52, 4702-4705.

[19] W. Siti, A. K. Khan, H.-P. M. De Hoog, B. Liedberg, M. Nallani, Org. Biomol. Chem. 2015, 13, 3202.

[20] W. Feng, L. Li, C. Yang, A. Welle, O. Trapp, P. A. Levkin, Angew.

Chemie - Int. Ed. 2015, 54, 8732-8735.

[21] Y. Zhang, W. Liu, Z. Zhao, Molecules 2013, 19, 306-315.

[22] R. S. Pandurangi, S. R. Karra, K. V. Katti, R. R. Kuntz, W. A Volkert, J. Org. Chem. 1997, 62, 2798-2807.

[23] R. S. Pandurangi, P. Lusiak, R. R. Kuntz, W. A. Volkert, J. Rogowski, M. S. Platz, J. Org. Chem. 1998, 63, 9019-9030. R. Rajagopalan, R. R. Kuntz, U. Sharma, W. A. Volkert, R. S Pandurangi, J. Org. Chem. 2002, 67, 6748-6757.

[25] C. W. Lange, H. F. Vanbrocklin, S. E. Taylor, S. E. Taylor, J. Label. Compd. Radiopharm. J Label Compd Radiopharm 2002, 45, 257268.

[26] K. Hashizume, N. Hashimoto, Y. Miyake, J. Org. Chem. 1995, 60, 6680-6681.

[27] M. Nishikawa, T. Nakano, T. Okabe, N. Hamaguchi, Y. Yamasaki, Y. Takakura, F. Yamashita, M. Hashida, Bioconjug. Chem. 2003, 14, 955-961.

M. A Stalteri, S. J. Mather, Eur. J. Nucl Med 1996, 23, 178-187. T. R. Sykes, T. K. Woo, R. P. Baum, P. Qi, A. A. Noujaim, J. Nucl. Med. 1995, 36, 1913-22

[30] T. R. Sykes, V. V Somayaji, S. Bier, T. K. Woo, C. S. Kwok, V. Snieckus, A. A. Noujaim, Appl. Radiat. Isot. 1997, 48, 899-906.

[31] H. J. Wester, K. Hamacher, G. Stöcklin, Nucl. Med. Biol. 1996, 23 365-72.

[32] L. Sun, J. Ding, W. Xing, Y. Gai, J. Sheng, D. Zeng, Bioconjug. Chem. 2016, 27, 1200-1204.

[33] M. Patra, L. S. Eichenberger, G. Fischer, J. P. Holland, Angew. Chemie - Int. Ed. 2019, 58, 1928-1933.

[34] R. Fay, M. Gut, J. P. Holland, Bioconjug. Chem. 2019, 30, 18141820.

[35] L. S. Eichenberger, M. Patra, J. P. Holland, Chem. Commun. 2019, $55,2257-2260$

[36] S. Klingler, R. Fay, J. P. Holland, J. Nucl. Med. 2020, 61, 10721078.

[37] S. Ito, Y. Tanaka, A. Kakehi, K. Kondo, Bull. Chem. Soc. Jpn. 1976 49, 1920-1923.

[38] Y. Zakon, L. Halicz, F. Gelman, Environ. Sci. Technol. 2013, 47 14147-14153

[39] R. B. Woodward, J. Am. Chem. Soc. 1941, 63, 1123-1126.

[40] L. F. Fieser, M. Fieser, S. Rajagopalan, J. Org. Chem. 1948, 13, 800-806.

[41] K. A. Usmani, E. D. Karoly, E. Hodgson, R. L. Rose, Drug Metab. Dispos. 2004, 32, 333 LP-339.

[42] D. J. Vugts, C. Klaver, C. Sewing, A. J. Poot, K. Adamzek, S Huegli, C. Mari, G. W. M. Visser, I. E. Valverde, G. Gasser, T. L. Mindt, G. A. M. S. van Dongen, Eur. J. Nucl. Med. Mol. Imaging 2017, 44, 286-295.

[43] T. Lindmo, E. Boven, F. Cuttitta, J. Fedorko, P. A. Bunn, J. Immunol. Methods 1984, 72, 77-89.

[44] J. P. Holland, E. Caldas-Lopes, V. Divilov, V. a Longo, T. Taldone, D. Zatorska, G. Chiosis, J. S. Lewis, PLoS One 2010, 5, e8859.

[45] M. Patra, S. Klingler, L. S. Eichenberger, J. Holland, iScience 2019 $13,416-431$ 


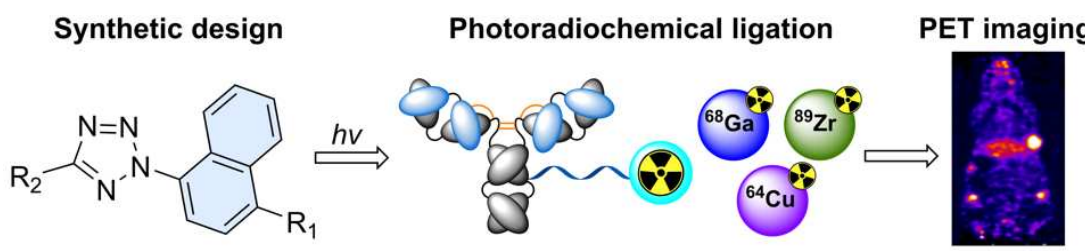

Tetrazole-based photolabelling of antibodies for PET. Tuning the photophysical properties of di-aryl tetrazole scaffolds can induce a bathochromic shift in the photoactivation window that facilitates protein ligation at long wavelengths. Photoactivatable metal binding chelates functionalised with a tetrazole are developed for applications in light-induced photoradiolabelling of monoclonal antibodies for positron emission tomography.
Rachael Fay and Jason P. Holland*

Page No. - Page No.

Tuning tetrazole photochemistry for protein ligation and molecular imaging 